\title{
A Research Note: Happiness by Age is More Complex than U-Shaped
}

\author{
Seppo Laaksonen ${ }^{1}$
}

Published online: 26 December 2016

(C) The Author(s) 2016. This article is published with open access at Springerlink.com

\begin{abstract}
Happiness varies with age, but there is no general agreement regarding the feature of the variation. Many studies have found that it is U-shaped such that there is a minimum between approximately 40 and 50 years of age. The result largely depends on the control variables used in the happiness modeling. Some authors do not even allow the use of any control variables, but the conventional theory of U-shaped studies stipulates the inclusion of such controls that essentially influence the basic living conditions of people. In this study, we do not strictly follow earlier findings but estimate our age-shape with different versions of them, using the data of 28 or 30 European countries. We also estimate a model without proper controls. This does not give any minimum age and thus supports some studies. Moreover, using any or all of our three controls some type of U-shape is found in most countries. Our U-shapes are not as simple as conventional research suggests. Minimum happiness can occur either below 40 years, or much above 50 years. A special feature is that the U-shape phenomenon holds better for males than for females. We also estimated models to see what happens after the minimum age happiness. In the case of gender models, the turning points for males are substantially lower than for females. This means that the old-age happiness of males stops to increase approximately at 70 years but more than 10 years later for females.
\end{abstract}

Keywords Cross-sectional happiness · Linear regression · Control variables · Three age variables · European Social Survey

Seppo Laaksonen

Seppo.Laaksonen@Helsinki.Fi

1 Social Research Department, University of Helsinki, Box 68, 00014 Helsinki, Finland 


\section{Introduction}

Happiness is a good variable for many purposes and can be interpreted against such living conditions as economy of the country, democracy, equality, health, employment, social and other security, education, family life and other personal characteristics. In such a case, happiness is measured as indicating long-term feelings, not only occasional or daily feelings. The questionnaire of the European Social Survey (ESS) uses the following formulation: "Taking all things together, how happy would you say you are?" The scale is from 0 (extremely unhappy) to 10 (extremely happy). This question has been found to work well, and it has been used in this study, although the ESS includes another question, i.e., life satisfaction. These two questions are highly correlated, but the average of happiness is slightly lower and the variability higher that is good in estimation.

Happiness thus can be examined from many perspectives, both at the macro and micro levels. This study is concerned with micro levels, that is, individuals age 15 years or older living at home. Our special focus is on age-related happiness, which has been studied earlier as well. Our main aim is to test the hypothesis presented by Blanchflower and Oswald (2004, 2008, 2009a), who simply state that 'Wellbeing is U-shaped in age.' This hypothesis has been criticized by several authors. Frijters and Beatton (2012) do not find this shape well in their study, and Glenn (2009) does not accept the statistical model used, especially from one point of view. In his opinion, no control variables should have been used in such estimation. Blanchflower and Oswald (2009b) responded to their critics with good arguments. We here follow these lines and agree that happiness models should be controlled for some personal characteristics but we present results also without proper controls. What the personal characteristics are is a special question and is discussed in Sect. 2. Respectively, the minimum happiness of this U-shaped curve is found between 40 and 50 years of age. This result is obtained from the survey data of some countries, such as the US and the UK.

Some studies do not explicitly estimate any age curve but find a similar structure from a table format after controlling for several personal and regional characteristics. An example is from China in which the happiness variable is subjective well-being measured with five categories (Sun et al. 2015).

The ESS gives new opportunities to examine this relationship for four reasons in particular. One reason is that the country coverage is large, that is, 30 countries the data of which are available from one round at minimum since 2008. Secondly, the data covers people of advanced age, which is rarely possible in ordinary surveys. The third good point is that the quality of control variables is fairly good, that is, for the ESS rounds 4-6 that are used in this study. The first three rounds are not used because the missingness was too high for two variables: income and education level. The fourth point is that the new sampling weights have been possible to use for all rounds since 2014. Hence, the estimates are expected to be more precise than those using the earlier design weights. These and other data features are explained in more detail in Sect. 4. Before that, in Sect. 3, we discuss the principles of our models, which always follow a weighted multivariate linear regression framework.

To explain happiness, we focus on age, but this parameter is considered only crosssectionally. A number of studies are also based on longitudinal frameworks that do not seem to change the base line substantially according to Cheng et al. (2014), among others. We do not either consider a cohort effect that could not be easily done since our data interval is fairly short. Our focus thus is on comparing age happiness with different models 
using four different patterns of personal characteristics. Gender is used in all models and, respectively, we compare age happiness by gender in the case of the largest model. Because there is no age limit in the ESS, we can look at older age happiness as well. We find that the age shape is more complex than that of the U-shaped favored studies. These results are in Sect. 5. We also present the results of the main models for each ESS country. Respectively, we estimate the core models by gender and find clear differences. Section 6 presents the conclusions.

\section{U-Shaped Literature and Modeling}

The literature on the age-happiness relationship is fairly recent. Clark and Oswald (1994, 655 ) found that for the UK, on average, happiness is lowest in a person's mid-thirties, that is, there is a U-shape in mental well-being. Gerdtham and Johannesson (2001) for Sweden and Blanchflower and Oswald $(2001,2004)$ for the US and the UK have reported a U-shape in age as well, as they have said in the conclusion (2004, 1381): "Happiness and life satisfaction are U-shaped in age. In both Britain and the US, wellbeing reaches a minimum, other things held constant, around the age of 40." Alesina et al. (2004) analyzed the determinants of happiness for over more than 10 years both for the US and 12 European countries. The focus of their study was not on age happiness, but they did find a significant U-shaped pattern.

The most comprehensive study to date is Blanchflower and Oswald (2008), who combined cross-sectional data for the US, Europe, and the World Value Survey. In total, they have over 60 countries, for which they all report a U-shape in happiness and age. There are more studies supporting this main result, although the age with lowest happiness varies to some extent (e.g., van Praag et al. 2003; Hayo and Seifert 2003). However, no complete consensus exists. Some reasons are due to the data, while some are due to the method applied.

Pedersen and Dall Schmidt (2009) use the European Community Household Panel to analyze the impact on self-reported satisfaction from a number of economic and demographic variables. In their model, a gender dummy comes out significantly negative in the southern European countries of Spain, Greece, Italy and Portugal. Living as a couple has a significantly positive impact on well-being in all of the countries studied. These researchers also employed other household variables, and their result does not support the finding in other data sets of a U-shaped profile of well-being over a life cycle.

Glenn (2009) criticizes the U-shape methodology regarding one of its key principles, i.e., how to use or whether to use control variables in the model. He argues that the appearance of this U-shaped curve of well-being is the result of the use of inappropriate and questionable control variables. The most clearly inappropriate control variable is marital status, the control of which, to a large extent, accounts for the U-shaped curve. Most researchers who have studied the relationship between being married and being happy believe that happiness affects marriage, and of course, a variable that is affected by the dependent variable should not be included as a control variable in a simple recursive model.

Glenn (2009) also says that control variables, such as income and education, are suspect because the relationship between them and well-being is likely to be partially spurious. He has other critical points about controls as well. The only clearly appropriate control variable is birth cohort, and when only it is controlled, the regression data become 
estimates of how the well-being of persons has actually changed as they have gone through the course of life. He argues that such estimates are much more useful than the counterfactual abstractions provided by Blanchflower and Oswald, and he concludes that they could make a very important contribution by redoing their analyses with birth cohort as the only control variable. He uses the American happiness data and finds that the results do not come close to the U-shaped pattern.

Blanchflower and Oswald (2009a, b) replied to Glenn's critiques. First, they explain in their response that Glenn's claim is incorrect. In many countries, the U-shape can be found without any control variables. They present a new result without personal controls for eight European countries and find a curve close to a U-shape. Moreover, Blanchflower and Oswald (2009a, b) believe Glenn's mistake has been to focus too heavily on the United States. It is known by researchers that the United States does not have a well-being U-shape in age if control variables are omitted. This was shown by Easterlin (2006) and was discussed in detail in an early version by Blanchflower and Oswald (2004). Strangely, Glenn looks only at data from a single nation, whereas the object of their original article was to find a relationship common across large numbers of nations (Blanchflower and Oswald 2008).

Second, they disagree with Glenn's methodological position, which seems to be that social scientists should not hold constant other factors when they study the relationship between well-being and age. We take up these two issues in turn.

Frijters and Beatton (2012) analyze the U-shape findings from several perspectives. Their first main finding is that the U-shape using conventional regressions disappeared when using fixed-effects because of a reverse causality issue: happiness-increasing variables, such as getting a job, a high income, and getting married, appear to happen mostly to middle-aged individuals who were already happy. This reverse causality appears in crosssections as inflated coefficients for income, marriage, and getting a job. To fit the actual age profile of happiness, the bias in coefficients for socio-economic variables forces the predicted age profile to become U-shaped. When one controls for fixed-effects, the nonlinearity all but disappears.

Happiness thus declines by age on average. The literature on ageing and happiness tends to conclude that there is a U-shape, with the elderly being better off than the middle aged, but this holds only if we control for other characteristics and life events that are typical of old age (e.g., lower education, worse health, lower income, loss of spouse). This raises the question of whether old age could be a golden age of life, a period with a deep sense of fulfillment and happiness, if people were able to avoid some negative aspects of old age.

\section{Model Implementation of this Study}

From the conclusion of Sect. 2, we thus can see that the existence of the U-shape may depend on the approach used in the study. One key question is the use of control variables in the model. Most authors consider that certain controls are required, such as income, education and a series of other personal characteristics (see also Lelkes 2006). However, no complete agreement concerning which personal characteristics should be included exists. Much depends on the data available. Gender is in almost all studies available and used. Education and objective income have been used, but their quality is not as comprehensive as in the ESS that we use in this study (Sect. 4). Several studies have included 
marital status and something about household and labor market status in the model (e.g., Alesina et al. 2004; Lelkes 2006).

Subjective personal health is one variable that is rarely used (an exception is the study by Sun et al. 2015), mainly because a good quality version of this variable is missing in the data. On the other hand, it is not clear whether it should be included. Moreover, there are some variables in ordinary social surveys that are too closely related to happiness and hence they should not be used as controls. General life satisfaction is naturally one such variable, but the variable 'feeling about household income nowadays' (called subjective income) is too closely related to happiness as well and hence not fair to use.

In this study, our purpose is not to solve the question about control variables and hence we compare four different alternatives cumulatively:
(A) No other controls except gender
(B) Adding objective income
(C) Adding education
(D) Adding subjective health

We do not include marital status and labor market variables, but the latter ones are implicitly included through income and education. We examined marital status but even though it is significant, the model with controls of gender, income and marital status removes the age curve very little and cannot be seen well in a graph. This model alternative thus would make our results more difficult to follow. On the other hand, the exclusion of marital status is done because its use has been criticized. Using the four alternatives only, the results are easier to interpret. We estimate these models without any strict hypothesis, and hence the model $\mathrm{A}$ is included as well.

The second issue is the model form. Many earlier studies used ordered logit (e.g., Alesina et al. 2004; Frijters and Beatton 2012), while some others used ordered probit or probit (e.g., Clark and Oswald 1994; Pedersen and Dall Schmidt 2009). The main reason for this form is that the dependent variable (happiness, well-being, life satisfaction) is categorized into four ordered groups (e.g., very happy, quite happy, satisfied, not happy at all). The happiness in this study (ordered from 0 to 10) can be interpreted to be continuous and hence we simply use weighted ordinary least square (WOLS) linear regression.

Because we use the cumulative ESS micro data of rounds 4, 5 and 6 (for the years 2008-2013), the model demands technical controls. One is the round itself and the second is the country. The number of countries is 30 except 28 in the specific country analysis (Table 2) because we did not include the two countries with only one ESS participation (i.e., Iceland, Italy). This was performed to obtain more robust country results.

We include in the model the post-stratified sampling weights that became available in 2014 for all rounds (ESS 2014). These weights are better than the formerly available design weights adjusted for nonresponse and frame errors because they are calibrated to the three true population margins, that is, gender, four age groups and three education levels.

Finally, because we are interested in the age and happiness relationship, we include age in the model with two alternatives:

1. Age and age-squared

2. Age, age-squared and age-cubed

The first alternative is specifically for testing how well the conventional U-shaped hypothesis fits with the ESS data in its four variable patterns, namely, A, B, C and D. The second alternative is for the same purpose but sheds some light on a possible other assumption, that is, whether the U-shaped hypothesis continues over the whole life of a 
person. It is possible to check this latter one better than in most data because there is no upper age limit in the ESS. The minimum age of the population is 15 years. Naturally, the survey covers only people who live at home and are able to answer the questions well enough. This requirement is in all surveys measuring happiness.

We thus estimate both the age minimum that is usually made in U-shaped research and also the turning point whenever it is estimable. This thus gives an age point when the happiness increase starts declining in the case such that the estimated minimum age is plausible (thus between 15 and 100).

\section{Data and Data Handling}

This paper uses the newest ESS data from three rounds. The ESS data quality has been improved during the six rounds from the point of view of the happiness study, especially because it requires good control variables. Hence, it is possible to estimate the age happiness better than before.

The earlier studies have used both multinational and national surveys but more often national such as Chinese Population Study (Sun et al. 2015), German Socio-economic panel (e.g., van Praag et al. 2003). Frijters and Beatton (2012) used the three national surveys in one study, that is, the American General Social Survey, the British Household Panel and the Hilda Survey (Survey (Household, Income and Labour Dynamics in Australia). The most common earlier multinational survey is Eurobarometer (e.g., Alesina et al. 2004). Blanchflower and Oswald $(2008,1734)$ mention that a statistically significant U-shape in happiness or life satisfaction by age is estimated separately for 72 countries but they do not present any details.

The happiness variable of these surveys is poorer than that of the ESS in categories. The same is concerned for control variables. Income consists typically of four or five categories (Alesina et al. 2004; Sun et al. 2015), except in the case of income surveys. The representativeness of most of these surveys is not either as good as in the ESS, which is well controlled both for the sampling and the fieldwork. The ESS data are also free for everyone to use, which guarantees the data quality too, giving easily possibility to check the estimates.

Lelkes (2008) used the data of the first ESS round when the quality of income and education were questionable; hence the results are presented at general level, thus avoiding critical aspects. Aslam and Corrado (2012) have used the ESS as well but for the third round, when the quality was not either high. They only include the EU countries in their study, but the ESS Europe is much larger. From the point of view of the quality of this study, the most important variable, i.e., objective income, has progressed since the third round. It is now measured as 10 deciles of each country. From the approach of this study, this is a good point because we do not need any overall income of the 30 countries. One drawback here, as in all studies, is missingness. Fortunately, this factor is less problematic now than in the case of Aslam and Corrado, when the income was missing for 22 percent of 20 EU countries. In our case, the missingness is approximately the same but for 30 countries. Most users, such as Aslam and Corrado, exclude the respondents with item nonresponse from the multivariate analysis. This is not well documented in the studies we have seen and it is thus difficult to know its impact on the results.

Our dependent variable, happiness, is answered well, its item nonresponse, on average, is less than 1 percent and the country differences are minor. The item nonresponse of age 
and gender is even smaller, and we do not lose many respondents from the regression analysis, respectively. We now have 155,500 respondents, and we do not lose any other respondents because we use the strategy that is not often used but is well argued.

All our further control variables are used as categorical so that we are able to include one or more missingness categories for each. Both the variable education and subjective health consist of five level codes and one missingness code. The missingness rate was below 1 percent for both. On the contrary, the most demanding control variable, i.e., objective income, received a much higher item nonresponse rate. This was possible to code into four categories, and their rates are as follows: refusals $11 \%$, do not know $7 \%$, missing for other reasons or unknown reasons 5\%. In the model, their estimates vary fairly logically. The happiness estimate for refusals, for instance, seems to be between the fifth decile and the sixth decile, thus fairly in the middle.

\section{Age Results}

Our main interest is to examine how well the U-shaped hypothesis holds true for the 30 European countries. All studies have not used any explicit models, but those that are thus have calculated the minimum age from the estimated regression coefficients of the age variables. The turning point is calculated, respectively, from the model that includes all three age variables.

Table 1 summarizes our results. Note that this or any other estimation result for all countries does not include significance indicators. This is to avoid too many figures, but fortunately all control variables in all models are highly significant $(p<.0001)$. The exception is Table 2 but insignificant estimates are there mentioned.

The U-shaped happiness is only found when using model $\mathrm{D}$, i.e., when health is a control variable together with gender, income and education level. When using the three age variables, the minimum age is, both here and in all other cases, a bit lower than in the case of the two age variables that correspond to the conventional strategy. This is because happiness is no longer increasing after the turning point, i.e., 71 years old.

On the other hand, the results are far from the U-shaped curve, unless health is not included in the model. Without any control except gender, no minimum age can be estimated. Thus, our results give support to Glenn's (2009) arguments.

We further illustrate the table results using a graph (Fig. 1). Happiness is rescaled from the regression estimates to correspond reasonably to the initial happiness of 30 countries. This clearly shows that happiness declines, but not linearly by age. When adding 1 or 2 control variables, a slight U-shape is found, but at fairly old ages, there is no clear correspondence to any common conventional result.

The curves do not differ essentially whether only income or both income and education are used. Instead, the profile of the curve dramatically changes when health is added. This

Table 1 The main results of age happiness for all 30 countries

$N S$ no plausible estimate

\begin{tabular}{|c|c|c|c|c|}
\hline & \multicolumn{4}{|c|}{ Models } \\
\hline & A & $\mathrm{B}$ & $\mathrm{C}$ & $\mathrm{D}$ \\
\hline Minimum of two ages & 76.3 & 60.6 & 57.8 & 45.0 \\
\hline Minimum of three ages & NS & 58.0 & 53.2 & 43.1 \\
\hline Turning point & 76.7 & 84.3 & 75.2 & 71.1 \\
\hline
\end{tabular}


Table 2 Estimated average ages and the turning point ages of different models
Model D includes all the four controls and the either two (first column) or three (third and fourth column) age variables, while model $\mathrm{C}$ is without the variable health and the age-cubed. The two or three age variables are not significant if the mark is 'NS' and the result is thus implausible. The countries are sorted by the conventional model $\mathrm{C}$ estimates

\begin{tabular}{|c|c|c|c|c|}
\hline \multirow[t]{2}{*}{ Country } & \multicolumn{3}{|c|}{ Minimum of three models } & \multirow{2}{*}{$\begin{array}{l}\text { Turning point } \\
\text { D }\end{array}$} \\
\hline & $\mathrm{D}$ & $\mathrm{C}$ & $\mathrm{D}$ & \\
\hline Denmark & 26.0 & 37.7 & 30.9 & 64.8 \\
\hline Ireland & 36.5 & 40.9 & 35.2 & 63.4 \\
\hline Sweden & 34.1 & 41.3 & 34.0 & NS \\
\hline Switzerland & 22.3 & 41.7 & 32.1 & 57.0 \\
\hline United Kingdom & 37.6 & 42.1 & 38.5 & 59.2 \\
\hline Belgium & 32.4 & 46.9 & 33.9 & NS \\
\hline Norway & 41.6 & 47.2 & 40.2 & NS \\
\hline Germany & 41.3 & 48.5 & 38.8 & 71.1 \\
\hline Turkey & 46.0 & 51.4 & 39.0 & 57.5 \\
\hline The Netherlands & 43.7 & 51.9 & 38.1 & 58.4 \\
\hline Finland & 41.4 & 52.1 & 41.2 & NS \\
\hline Cyprus & 38.6 & 55.8 & 35.9 & 61.0 \\
\hline France & 50.9 & 58.7 & 46.9 & 82.4 \\
\hline Czech & 38.0 & 60.6 & 36.5 & 67.9 \\
\hline Slovakia & 48.3 & 61.4 & 43.1 & 67.3 \\
\hline Hungary & 46.0 & 62.3 & 40.6 & 64.0 \\
\hline Greece & 50.3 & 63.0 & 43.9 & 65.6 \\
\hline Slovenia & 50.6 & 63.0 & 48.6 & NS \\
\hline Estonia & 46.0 & 63.1 & 48.8 & NS \\
\hline Bulgaria & 52.6 & 63.9 & 48.0 & 73.7 \\
\hline Russia & 48.3 & 65.5 & 42.9 & 66.7 \\
\hline Spain & 46.8 & 67.5 & 40.1 & 60.4 \\
\hline Poland & 47.2 & 70.4 & 54.6 & NS \\
\hline Lithuania & 50.4 & 73.7 & 43.3 & 63.9 \\
\hline Croatia & 51.4 & 74.5 & 43.3 & 61.3 \\
\hline Ukraine & 58.7 & 82.0 & 57.3 & NS \\
\hline Portugal & 62.4 & 87.1 & 52.8 & 63.2 \\
\hline Israel & 49.3 & 90.6 & 41.9 & 62.6 \\
\hline
\end{tabular}

finding means that health and happiness are inversely related to each other. We do not have any precise opinion whether health should be included in this model but rather suggest estimating both models. Thus, the model should be estimated with the appropriate personal characteristics variables without and with health and then interpreted well.

We find some support for the U-shape curve over 30 countries, but it varies considerably between countries. This is seen in Table 2 that is for 28 countries. The table does not include the smallest models A and B. However, we estimated model A for each of 28 countries to get understanding for the results of the U-shape founders who used UK data. This is of special interest since the U-shape curve is criticized (cf. Sects. 1 and 2). The conventional truth that the minimum happiness is between 40 and 50 years was found in the UK, in Ireland and in Switzerland, a bit above 50 years in Norway, Turkey and Germany. A U-shape is found also in the Netherlands (60 years), in Belgium (64), in France (68) and in Sweden (32) but not in any other countries. We thus can say that 
Fig. 1 Graphical illustration of age happiness with four models. The $y$-axis approximately corresponds to the initial happiness scale of the questionnaire

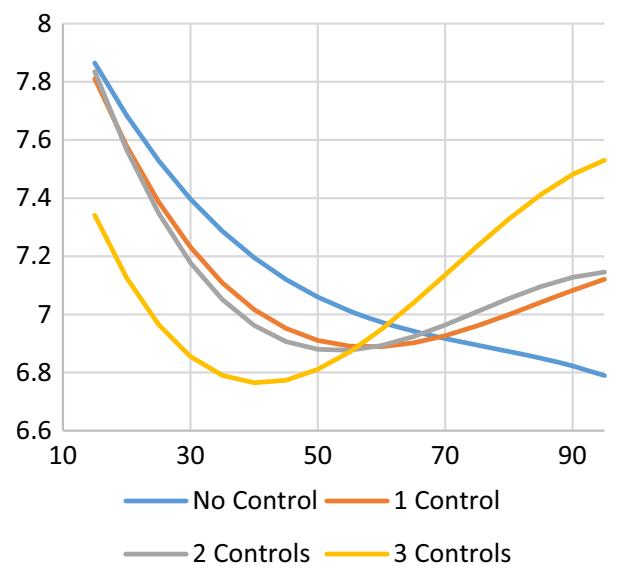

happiness is not generally U-shaped without controls. Using appropriate personal controls it will be more evidenced (Table 2).

When looking at the column with model C, i.e., with the most conventional strategy, the U-shape with the middle age minimum is found in approximately one half of the countries. Many more countries are there when health is included in the model, but the minimum is surprisingly low in Switzerland and Denmark, the countries with a high happiness average.

The third column, in which the three age variables are included, gives the best evidence for the U-shape theory because the minimum in most countries is approximately in the middle age. This model yields also a turning point for many countries, with the lowest ages being below 60 years (e.g., Switzerland, Turkey) and highest being approximately 70 years. These results can be interpreted as plausible, that is, happiness no longer increases after a certain age. A drawback is that the turning point could not be estimated for several countries, although the other estimates are fairly ordinary.

All results so far are for both genders, but gender is a control variable in all models. The happiness estimate of all models for females is higher than for males, but it varies by the model and, naturally, by country; however, here we do not consider gender differences by country. We instead have estimated the two main models for both genders independently, and the main results are presented in Table 3 and Fig. 2, respectively.

The table results already show that the U-shape relationship is not similar by gender. However, it is much better found for males than for females. As in the case of the models for both genders, the minimum age is lower when using the model with the subjective health control variable. Interestingly, the turning points for males are substantially lower than for females, and model D does not give any plausible estimate. This means that the old-age happiness of females increases as long as they are able to answer survey questions.

Table 3 Minimum ages and turning point ages by gender

NS no plausible estimate

\begin{tabular}{lllllllll}
\hline & \multicolumn{2}{l}{ Model C (income, education) } & & \multicolumn{2}{c}{ Model D (health included) } \\
\cline { 2 - 3 } & 2 ages & 3 ages & Turning & & 2 ages & 3 ages & Turning \\
\hline Female & 64.5 & 64.7 & NS & & 46.4 & 43.2 & 80.7 \\
Male & 56.3 & 51.7 & 73.9 & & 43.8 & 39.7 & 66.5 \\
\hline
\end{tabular}



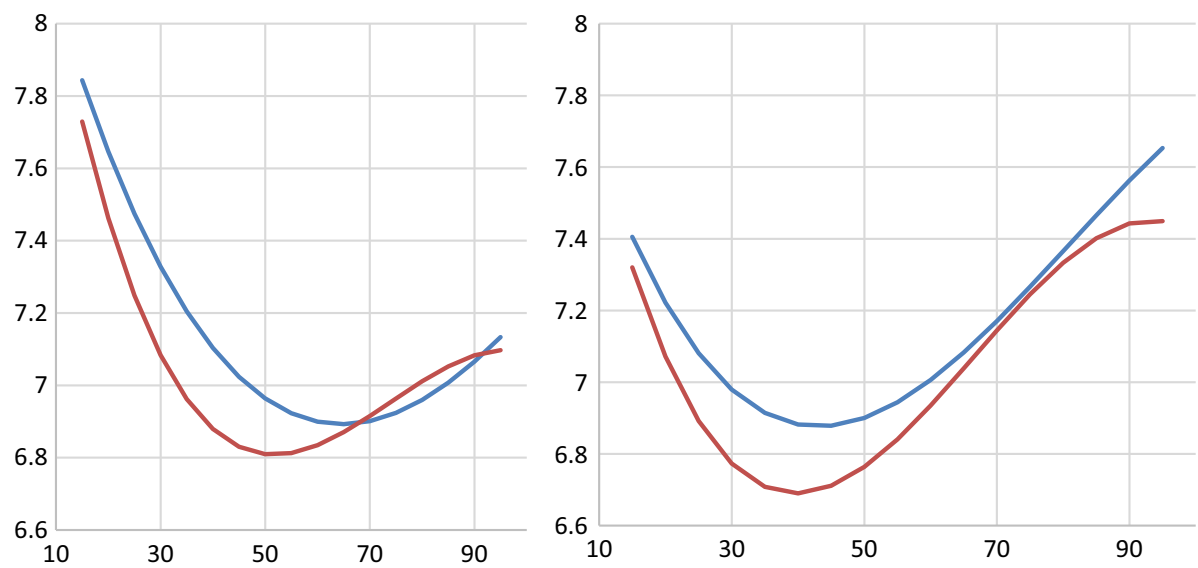

Fig. 2 Age curves for females (upper curve) and males calibrated to the happiness difference by the model. The left panel and right panel are from model $\mathrm{C}$ and model $\mathrm{D}$, respectively

\section{Conclusion}

The aim of this study was to examine the age-happiness relationship more widely than has been conventionally performed. Conversely, we used the integrated cumulative micro data of the ESS, which initially covers 30 countries. Because its data quality has been improved since round 4 (2008-2009), we have been able to use the data from three rounds (until 2012-2013). Most of these countries have participated for all three rounds, but a number only participated for two or one. We have excluded the countries with only one participation from the country analysis because their estimates may be too uncertain, and hence there are 28 countries in our country estimations.

The majority of researchers report a U-shape and call the U-shaped age effect a typical finding in happiness regressions. Blanchflower and Oswald (2001, 2004, 2008, 2009a, b), in particular, have received such results. It however is a mystery (Frijters and Beatton 2012) or the U-shape in middle age might be weak only. Glenn (2009) also criticises the model approach used. We thus can conclude that this topic is exciting, and further studies are welcome. It is for example obvious that marginalized and solitary people are less happy than those with good family relationships and friends but such study is not easy to implement.

The use of controls can be justified following the arguments by Lelkes (2008): It is not ageing as such, which results in declining happiness, but rather the circumstances associated with ageing.

The happiness in earlier studies is measured in different ways and with different scales. In the ESS, the scale is larger than in most other surveys, from 0 (extremely unhappy) to 10 (extremely happy). This study investigates the U-shaping with four different models. The narrowest model, without remarkable control variables, does not find any U-shape, but when adding one rich control, i.e., objective income, a U-shape curve appears. This curve continues to appear when adding the two other controls, but its form changes at the same time.

The missingness in the model estimation is minimal, since the variables of happiness, age and gender are nearly complete. On the other hand, the control variables income, 
education and health are applied as categorical giving opportunity to include missingness codes in each. Hence these variables are fully observed.

The conventional literature has used two age variables, i.e., age and age-squared, but in this study, we add a third one, i.e., age-cubed. This study provides an opportunity to specify more clearly the age-happiness relationship over a whole lifetime. It is possible because the ESS has no upper age limit, as in many other surveys. Our conclusion from the data of all countries is that the U-shape is not as simple as some research suggests, and thus the minimum happiness is not necessarily at approximately $40-50$ years old. Minimum happiness can occur earlier or much later, depending on the model used, and the country concerned. The U-shape is clearly found in approximately one half of the 28 countries. A special feature is that the U-shape phenomenon holds better for males than for females.

The findings of the study, of course, could be used in policy implications. We here cannot analyze these issues in details but the basic idea is to try to make people happier, by providing more education and better health services, and increasing income, among others. In other words, age is a necessary control for the identification of other variables of interest, such as job status, work experience, health status, income and education. Moreover, we find that the implications of this study for policy makers vary relatively much between countries.

Open Access This article is distributed under the terms of the Creative Commons Attribution 4.0 International License (http://creativecommons.org/licenses/by/4.0/), which permits unrestricted use, distribution, and reproduction in any medium, provided you give appropriate credit to the original author(s) and the source, provide a link to the Creative Commons license, and indicate if changes were made.

\section{References}

Alesina, A., Di Tella, R., \& MacCulloch, R. (2004). Inequality and happiness: Are Europeans and Americans different? Journal of Public Economics, 88(9-10), 2009-2042.

Aslam, A., \& Corrado, L. (2012). The geography of well-being. Journal of Economic Geography, 12, 627-649.

Blanchflower, D. G., \& Oswald, A. J. (2001). Well-being over time in Britain and the USA. National Bureau of Economic Research (NBER). Working Paper No. 7487.

Blanchflower, D. G., \& Oswald, A. J. (2004). Well-being over time in Britain and the USA. Journal of Public Economics, 88(7-8), 1359-1386.

Blanchflower, D. G., \& Oswald, A. J. (2008). Is well-being U-shaped over the life cycle? Social Science and Medicine, 66, 1733-1749.

Blanchflower, D. G., \& Oswald, A. J. (2009a). The U-shape without controls. Coventry: University of Warwick, Department of Economics, The Warwick Economics Research Paper Series (TWERPS).

Blanchflower, D. G., \& Oswald, A. J. (2009b). The U-shape without controls: A response to Glenn. Social Science and Medicine, 69, 486-488.

Cheng, T. J., Powdthavee, N., \& Oswald, A. J. (2014). Longitudinal evidence for a midlife nadir in human well-being: Results from the four data sets. IZA Discussion Paper No. 7942. http://ftp.iza.org/dp7942. pdf.

Clark, A. E., \& Oswald, A. J. (1994). Unhappiness and unemployment. Economic Journal, 104, 648-659.

Easterlin, R. A. (2006). Life cycle happiness and its sources. Intersections of psychology, economics, and demography. Los Angeles: University of Southern California.

ESS_European Social Survey. (2014). Documentation of ESS post-stratification weights. http://www. europeansocialsurvey.org/docs/methodology/ESS_post_stratification_weights_documentation.pdf

Frijters, P., \& Beatton, T. (2012). The mystery of the U-shaped relationship between happiness and age. Journal of Economic Behavior \& Organization, 82, 525-542.

Gerdtham, U.-G., \& Johannesson, M. (2001). The relationship between happiness, health, and socio-economic factors: Results based on Swedish microdata. Journal of Behavioral and Experimental Economics, 30(6), 553-557. 
Glenn, N. (2009). Is the apparent U-shape of well-being over the life course a result of inappropriate use of control variables. Social Science and Medicine, 69, 481-485.

Hayo, B., \& Seifert, W. (2003). Subjective economic well-being in Eastern Europe. Journal of Economic Psychology, 24(2003), 329-348.

Lelkes, O. (2006). Tasting freedom: Happiness, religion and economic transition. Journal of Economic Behavior \& Organization, 59(2), 173-194.

Lelkes, O. (2008). Happiness across the life cycle: Exploring age-specific preferences. European Centre. Policy Brief March. http://www.euro.centre.org/data/1207216181_14636.pdf

Pedersen, P. J., \& Dall Schmidt, T. (2009). Happiness in Europe: Cross-country differences in the determinants of subjective well-being. IZA Discussion Paper No. 4538. Bonn.

Sun, S., Chen, J., Johannesson, M., Kind, P., \& Burström, K. (2015). Subjective well-being and its association with subjective health status, age, sex, region and socio-economic characteristics in a Chinese Population Study. Journal of Happiness Studies. doi:10.1007/s10902-014-9611-7.

van Praag, B. M. S., Frijters, P., \& Ferrer-i-Carbonell, E. (2003). The anatomy of subjective well-being. Journal of Economic Behavior \& Organization, 51, 29-49. 